\title{
A ideologia de Marx e o discurso de Foucault: convergências e distanciamentos'
}

SÉRGIO BACCHI MACHADO"

\section{Resumo}

Efetua-se um mapeamento dos conceitos de ideologia e discurso nas obras de Marx e Foucault, respectivamente. Procede-se também a uma recapitulação da análise marxiana da inversão das leis de apropriação como substrato da destruição de uma forma ideológica específica; assim como se retoma, na obra foucaultiana, a arqueologia da relação médico-paciente como exemplo de configuração de um determinado campo discursivo. Por fim, indica-se um distanciamento e uma convergência entre os conceitos em questão.

Palavras-chave: Ideologia. Discurso. Marx, K. (1818-1883). Foucault, M. (19261984).

\footnotetext{
* Psicólogo e mestre pela USP.

1 Evidentemente, a primeira parte do título deve ser tomada no registro lúdico, uma vez que não pretendemos afirmar nenhum caráter "ideológico" da obra de Marx, nem, tampouco, efetuar uma "análise de discurso" da obra foucaultiana, como ficará claro no decorrer do texto.
} 


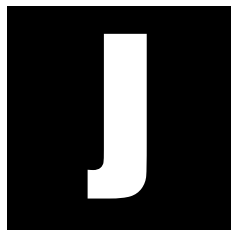

Já se tornou lugar-comum afirmar que as obras de grandes pensadores - como certamente o são Marx e Foucault possibilitam um leque infindável de interpretações. Tantas e tão diversificadas leituras constituem a prova viva de profundidade e alcance de seus textos originais. Ao mesmo tempo, é patente que, quanto mais se escreve sobre O capital (MARX, 2002), mais novos detalhes são iluminados; quanto maior é o número de comentários sobre A história da loucura (FOUCAULT, 2002), mais rica se torna essa "história". Sabemos, ainda, que as melhores interpretações não se restringem a "dizer novamente" o conteúdo do original, mas criam novos e penetrantes planos com base na obra interpretada.

Contudo, a massa crescente de interpretações apresenta também um lado negativo. Isso se dá quando os autores originais são como que obstruídos por noções vulgares que se lhes atribuem, impedindo o brilho de suas ideias inovadoras. Perde-se, com isso, o solo firme do qual novas leituras e criações podem se elevar, dando-se lugar a caricaturas grotescas. Dessa forma, Heidegger se torna um apóstolo da angústia; Freud, o senhor que reduz o mundo ao sexo; Bergson, o antípoda ferrenho da ciência moderna, e assim vamos...

Acreditamos que esse tipo de caricatura, longe de ser inócuo, traz em si um efeito de "trava" no trabalho de pensamento. A fim de contrapormonos a esse viés grosseiro, nos propusemos a escrever este trabalho. Para tanto, escolhemos como objeto dois conceitos estratégicos nas obras de Marx e Foucault: ideologia e discurso. Muito influiu, ainda, em nossa escolha a constatação de uma frequente indiscriminação no uso desses operadores, perdendo-se, assim, nada menos que o principal: a relação do conceito com a obra e o rigor tão prezado pelos autores. No entanto, não nos preci- 
pitaremos afirmando uma exterioridade total entre ideologia e discurso, de modo que nos manteremos abertos a possíveis convergências.

Pretendemos, no decorrer deste estudo, mapear os conceitos de ideologia na obra de Marx e de discurso na produção de Foucault, recuperando o que consideramos suas silhuetas originais. Para tanto, também lançaremos mão de um exemplo concreto para cada conceito, retirado da própria obra de seu respectivo autor.

II

Em suas Teses contra Feuerbach, Marx e Engels colocam que:

[...] a essência humana não é abstrata residindo no indivíduo único. Em sua efetividade é o conjunto das relações sociais. Feuerbach, que não entra na crítica dessa essência efetiva, é por isso forçado [...] a abstrair o curso da história e fixar o ânimo religioso como para-si, pressupondo um indivíduo humano, abstrato e isolado. (MARX; ENGELS, 1974, p. 58)

Com esse ataque, Marx diferencia-se radicalmente da corrente materialista de Feuerbach. Com efeito, a partir de então, ele desdenhará a filosofia que se propõe a pesquisar o núcleo humano das configurações espirituais. Essa ruptura, no entanto, é mais significativa do que parece à primeira vista, pois ela implica o abandono de uma grande tradição filosófica centrada no sujeito. Segundo essa tradição, "o espírito seria, antes de mais nada, autoconsciência, sendo seu solo a presença absoluta de si em si mesmo, onde se apresentam os atributos do autocentramento e da interiorização" (BIRMAN, 2003, p. 155). No estudo da história, a filosofia do sujeito exerceu uma influência tal que se fez:

[...] da história recente a finalidade da história anterior; é assim, por exemplo, que se atribui à descoberta da América o seguinte objetivo: ajudar a eclodir a Revolução Francesa; dessa maneira, confere-se então à história seus fins particu- 
lares e dela se faz 'uma pessoa ao lado de outras pessoas'. (MARX; ENGELS, 2007, p. 47)

Para a dialética materialista, o homem não pode ser entendido como uma abstração, nem tampouco a realidade como o desenvolvimento terreno dessa especulação substancialista do ser humano. Pelo contrário, o sujeito passa a ser dimensionado em sua concretude, ou seja, enquanto criador da realidade social que, ao mesmo tempo, é criado por esta. Desse modo, a atividade humana sensível, isto é, a práxis, é peça fundamental para a compreensão dialética do homem como ser social. Assim, "cada geração, por um lado, continua o modo de atividade que the é transmitido, mas em circunstâncias radicalmente transformadas, e, por outro lado, ela modifica as antigas circunstâncias entregando-se a uma atividade radicalmente diferente" (MARX; ENGELS, 2007, p. 47).

A atividade social, por sua vez, relaciona-se, para Marx, intrinsecamente com a esfera econômica:

Produzir a vida, tanto a sua própria vida pelo trabalho, quanto a dos outros pela procriação, nos parece portanto, a partir de agora, como uma dupla relação: por um lado como uma relação natural, por outro como uma relação social - social no sentido em que se estende com isso a ação conjugada de vários indivíduos, sejam quais forem suas condições, forma e objetivos. Disso decorre que um modo de produção ou um estágio industrial determinados estão constantemente ligados a um modo de cooperação ou a um estádio social determinados, e que esse modo de cooperação é, ele próprio, uma 'força produtiva'; decorre igualmente que a massa das forças produtivas acessíveis aos homens determina o estado social, e que se deve por conseguinte estudar e elaborar incessantemente a 'história dos homens' em conexão com a história da indústria e das trocas. (MARX; ENGELS, 2007, p. 23-24) 
A esfera econômica permite, assim, a conexão de todas as dimensões da vida social, de modo que a própria unidade da realidade social encontra sua condição de possibilidade na estrutura econômica.

O que distingue as diferentes épocas econômicas não é o se faz, mas como, com que meios de trabalho se faz. Os meios de trabalho servem para medir o desenvolvimento da força humana de trabalho e, além disso, indicam as condições sociais em que se realiza o trabalho. Os meios mecânicos, que, em seu conjunto, podem ser chamados de sistema ósseo e muscular da produção, ilustram muito mais as características marcantes de uma época social de produção que os meios que apenas servem de recipientes da matéria objeto de trabalho e que, em seu conjunto, podem ser denominados de sistema vascular da produção, como, por exemplo, tubos, barris, cestos, cântaros etc. (MARX, 2002, p. 214)

Portanto, a dialética toma o homem como sujeito objetivo, isto é, como ser que, ao transformar a natureza pelo trabalho, cria a realidade social. Com efeito, para Marx, a economia é a estrutura primordial de objetivação dos homens. Entretanto, "o primado da economia não decorre de um superior grau de realidade de alguns produtos humanos, mas do significado central da práxis e do trabalho na criação da realidade humana" (KOSIK, 2002, p. 122). Esse posicionamento, sem dúvida, difere radicalmente de uma certa vertente estabelecida por alguns marxistas segundo os quais os fenômenos culturais devem ser integralmente reduzidos ao simples fator econômico.

O homem como ser social e o primado da economia constituem as premissas para o conceito marxista de ideologia. Acompanhemos a seguinte enunciação que sintetiza as duas premissas apontadas: "Se examinarmos a sociedade burguesa em seu conjunto, o que se apresenta sempre, como resultado último do processo social de produção, é a própria sociedade. Vale dizer, o próprio homem nas suas relações sociais." (MARX, 1958, apud KOSIK, 2002, p. 195). Com isso, abre-se uma porta 
para se considerar também o universo das ideias um seguimento do processo social de produção. Sem dúvida, as ideias podem ser vistas, então, como uma criação específica de homens que se constituem em relações concretas. Assim, elas perdem sua aparente autonomia para se tornarem produtos históricos de homens que, ao mesmo tempo, fazem a história.

Mas estamos nos adiantando; recuemos um pouco. Marx parte do pressuposto de que o trabalho é o agente determinante na diferenciação entre o homem e o animal, de modo que, ao transformar a natureza por meio de um plano que antecipa a ação, o homem "adquire" sua humanidade. Esse planejamento intencional pode ser analisado por dois ângulos: primeiro, à medida que se diferencia da natureza, o homem passa a temê-la; segundo, ele estabelece relações com outros homens que, como ele, temem e transformam o mundo externo.

Assim, a consciência é, antes de mais nada, apenas a consciência do meio sensível mais próximo e de uma interdependência limitada com outras pessoas e outras coisas situadas fora do indivíduo que toma consciência; é ao mesmo tempo a consciência da natureza que se ergue primeiro em face dos homens como uma força fundamentalmente estranha [...]. (MARX; ENGELS, 2007, p. 25)

Nesse momento, as ideias e representações encontram-se ainda diretamente voltadas à atividade material, à ação sob uma perspectiva de conjunto. Desse modo, tão antiga quanto a consciência é a linguagem, a qual possibilita a coordenação dos modos coletivos de agir frente ao mundo externo. Entretanto, com o aprimoramento da divisão social do trabalho, opera-se uma curiosa repartição: aquela entre o trabalho material e o intelectual. "A partir desse momento, a consciência pode de fato imaginar que é algo mais do que a consciência da prática existente, que ela representa realmente algo, sem representar algo real" (MARX; ENGELS, 2007, p. 26). 
A divisão social entre trabalho material e intelectual é, por sua vez, atravessada desde seu princípio por uma outra repartição grave o suficiente para rasgar o tecido social por inteiro. Trata-se da divisão entre exploradores e explorados, isto é, aquela entre os que se aproveitam do trabalho alheio e os que trabalham para outros. Marx e Engels abrem "O manifesto comunista com a contundente afirmação de que a história de todas as sociedades que já existiram é a história de luta de classes" (MARX; ENGELS, 1998, p. 9). Em A ideologia alemã (MARX; ENGELS, 2007) - apesar de escrita antes de $\mathrm{O}$ manifesto -, a dominação material de uma classe sobre outra é dimensionada por meio de seu complemento necessário: a ideologia. Nesse sentido, as ideias dominantes em uma determinada época constituem a expressão representativa da dominação material.

Os pensamentos da classe dominante são também, em todas as épocas, os pensamentos dominantes; em outras palavras, a classe que é o poder material dominante numa determinada sociedade é também o poder espiritual dominante. A classe que dispõe dos meios da produção material dispõe também dos meios da produção intelectual, de tal modo que o pensamento daqueles aos quais são negados os meios de produção intelectual está submetido também à classe dominante. (MARX; ENGELS, 2007, p. 48)

Podemos constatar pelo recorte de Marx que a ideologia não se identifica necessariamente com o propagandismo calculado. A ideologia se efetiva como expressão de uma classe em seu posicionamento limitado - ainda que dominante - com as demais. Certamente a manipulação calculista é uma possibilidade abarcada pelo conceito de ideologia, porém em hipótese alguma esses são termos equacionáveis.

Consideremos agora a questão de um outro ponto de vista. A burguesia como classe dominante diferencia-se de seu antecedente por não ser um estamento, de forma que suas alianças e defesas não podem se dar no plano local, mas no nacional. A burguesia necessita, portanto, de um organismo regulador que assegure sua propriedade e seus interesses 
no plano nacional; de uma instituição que lance seus tentáculos por todo o tecido social e contenha as demais classes usando, em último caso, a violência, mas preferindo sempre a repressão por meio de ideias. Universalidade e igualdade deve ser seu lema, e este deve ser repetido até se entranhar no cérebro de cada indivíduo. Sabemos que esse organismo chama-se Estado moderno.

Sendo o Estado, portanto, a forma pela qual os indivíduos de uma classe dominante fazem valer seus interesses comuns e na qual se resume toda a sociedade civil de uma época, conclui-se que todas as instituições comuns passam pela mediação do Estado e recebem uma forma política. Daí a ilusão de que a lei repousa na vontade, e, mais ainda, em uma vontade livre, destacada da sua base concreta. (MARX; ENGELS, 2007, p. 74)

\section{III}

A fim de facilitar o entendimento do conceito de ideologia de Marx, efetuaremos neste item uma mediação no interior mesmo da obra marxiana. Falaremos da circulação de mercadorias, ou seja, da rede de trocas entre as mercadorias. Porém, como compreender o movimento da circulação sem antes avaliarmos a própria categoria mercadoria? Para isso, teremos que transitar também por alguns fundamentos da teoria do valor marxiana.

Logo no início de O capital, Marx (2002) foca a forma-mercadoria. Como objeto palpável, sensível, a mercadoria atende a necessidades específicas: uma cadeira serve para sentar, com uma determinada quantidade de aço pode-se produzir o casco de uma embarcação, um livro espera ser lido. A qualidade desse uso potencial, Marx denomina valor de uso. Portanto, o valor de uso corresponde à esfera qualitativa da mercadoria.

Marx nos faz observar, então, que, independentemente de seus valores-de-uso, as mercadorias são intercambiáveis entre si. A questão 
pode ser exposta da seguinte maneira: uma quantidade $\mathrm{x}$ de cadeiras pode ser trocada por uma quantidade y de aço, que, por sua vez, pode ser convertida em uma quantidade $z$ de livros. Já essa quantidade $z$ de livros pode tanto ser trocada por uma quantidade determinada de outra mercadoria qualquer quanto se converter na mercadoria inicial do elo, ou seja, x cadeiras. A capacidade dessas mercadorias de trocarem-se umas pelas outras induz a pensar que há nelas uma propriedade comum, um fator quantitativo geral e impalpável. Essa propriedade genérica das mercadorias recebe o nome de valor de troca, ou, simplesmente, valor.

$\mathrm{O}$ valor de uma mercadoria refere-se às suas relações de troca, sendo independente de suas características físicas, geométricas ou de qualquer outra natureza. Nesse sentido, o valor de troca encontra-se na exterioridade do valor de uso ${ }^{2}$. "Põe-se de lado os valores-de-uso das mercadorias, quando se trata da relação de troca entre elas" (MARX, 2002, p. 59). Por conseguinte, os valores de troca referem-se a padrões meramente quantitativos, enquanto os valores de uso, posto que inseridos na esfera qualitativa, são irredutíveis uns aos outros.

A solução para a questão do valor enquanto magnitude quantitativa abstrata é encontrada por intermédio de uma nova abstração relacionada à forma-mercadoria. Ora, sendo todas as mercadorias produtos de trabalho, não se poderia abstrair as qualidades específicas desses trabalhos, reduzindo todos a uma espécie geral e homogênea? Realmente, no trabalho humano abstrato as mercadorias encontram seu denominador comum; todas elas passam a ser vistas, então, como corporificações dessa espécie geral de trabalho. Em outras palavras, os produtos tornam-se valores-mercadorias.

2 Um olhar mais rigoroso mostra, entretanto, que essa exterioridade não é total, pois uma mercadoria qualquer, para ser potencialmente "trocável", deve atender a alguma necessidade social e, portanto, ter valor de uso para alguém. Entretanto, o valor de uso vigora, dessa maneira, como um mero índice da possibilidade de troca entre as mercadorias. 
Podemos agora retomar a questão inicial tendo por base as categorias mercadoria e valor. A circulação mercantil simples é o processo em que a mercadoria converte-se em dinheiro e o dinheiro converte-se em mercadoria num fluxo incessante. Marx caracteriza o ciclo da circulação simples como mercadoria-dinheiro-mercadoria (M-D-M), de forma que, ao menos aparenteme nte, não há criação de valor excedente. Por outro lado, a circulação ocorre por meio de uma série de acordos voluntários entre os indivíduos envolvidos. "Só é possível apropriar-se de mercadorias alheias, ou seja, de trabalho alheio, mediante a alienação do próprio [trabalho], o processo de apropriação da mercadoria, que precede a troca, parece ser a origem da apropriação, [...] o título jurídico da propriedade" (MARX, 1978, p. 435).

Dessa maneira, os economistas da escola clássica puderam - e nisso foram seguidos pelos economistas burgueses - dizer que "a propriedade individual sobre o resultado do próprio trabalho constitui a condição básica da sociedade burguesa" (MARX, 1978, p. 435). Com efeito, ao se depararem uns com os outros no mercado, os proprietários se vêem como iguais; não há violência nas trocas, sendo as únicas diferenças entre os indivíduos envolvidos as necessidades e valores de uso de cada um. Essas diferenças, longe de constituírem qualquer conflito, possibilitam a liberdade de cada um na satisfação das próprias necessidades por meio dos valores de uso que lhe convém. Mas isso ainda não é tudo: à medida que um produtor satisfaz o outro com seus produtos, ele também serve ao outro; e, como todos acabam por servir a todos, impera uma perfeita reciprocidade entre eles. Desse modo, o âmbito da circulação é marcado pela igualdade, pela liberdade e pela reciprocidade. Isso tudo nos dizem os economistas, essas são suas ideias e elas se enraízam nas próprias leis do intercâmbio. "Os economistas expressam isso do seguinte modo: cada um busca seu interesse privado, e assim, sem o saber, serve ao interesse privado de todos, ao interesse geral" (MARX, 1977, p. 83). 
Marx, porém, não restringe sua análise à circulação mercantil simples, evitando, desse modo, a adesão à ideologia burguesa. Para ele, a circulação corresponde à esfera mais abstrata do modo de produção capitalista; nela se "esconde todo um mundo, o mundo das relações do capital" (MARX, 1978, p. 23). Por conseguinte, o movimento de Marx não pode ser outro que não o exame das relações de produção soterradas pela circulação e pela ideologia. Ao penetrar nesse mundo, ele logo percebe que ao lado da forma simples da circulação simples $M-D-M$ encontra-se uma outra diversa, que pode ser sintetizada na fórmula D-M-D, ou seja, dinheiro-mercadoria-dinheiro. Nesse segundo circuito, dinheiro converte-se em mercadoria e mercadoria reconverte-se em dinheiro, em uma espécie de inversão do primeiro ciclo. Porém, a característica mais marcante do circuito D-M-D é a expansão do valor, uma vez que o último elemento $D$ é quantitativamente superior ao primeiro. Esse ciclo, no entanto, não encontra seu termo com esse acréscimo: ele será prolongado em um novo ciclo, ou, se preferirmos, em uma continuação dele mesmo. Portanto, "o dinheiro que se movimenta de acordo com esta última circulação transforma-se em capital, vira capital e, por sua destinação, é capital" (MARX, 2002, p. 178).

Para que o dinheiro possa se transformar em capital e, desse modo, expandir seu valor, é preciso que o possuidor de dinheiro ache, dentro do âmbito da circulação, no mercado, uma mercadoria um tanto especial. Considerando que o capital é um valor em busca de mais-valor, a única coisa capaz de apresentar-se diante dele como valor de uso seria algo com capacidade de reproduzi-lo e multiplicá-lo. O uso que o capital fará dessa mercadoria só pode corresponder ao sentido de sua existência: criar mais-valor, ou seja, corporificar trabalho. Pois bem, essa mercadoria existe e chama-se força de trabalho. Ao usá-la, o possuidor do dinheiro torna-se capitalista, ao passo que o dinheiro se transforma em capital.

A transação ocorre dentro da esfera da circulação. Não possuindo meios de produção como o capitalista, o indivíduo vende a mercadoria que 
detém: a força de trabalho contida em seu corpo vivo. Contudo, ele não aliena sua mercadoria para sempre - uma vez que isso implicaria a venda de si mesmo, ou seja, tornar-se escravo -, mas temporariamente. Assim, na condição de homem livre, ele vende sua força de trabalho por um tempo determinado, mantendo-se, em longo prazo, como seu proprietário.

Como ocorre com toda mercadoria, o valor da força de trabalho equivale ao tempo de trabalho nela corporificado. Dessa maneira, a conservação e reprodução da força de trabalho correspondem à manutenção do corpo vivo do seu proprietário, ou seja, do trabalhador. Para sustentarse, todo indivíduo necessita de uma quantidade mínima de meios de subsistência; assim:

O tempo de trabalho necessário à produção da força de trabalho reduz-se, portanto, ao tempo de trabalho necessário à produção desses meios de subsistência, ou o valor da força de trabalho é o valor dos meios de subsistência necessários à manutenção de seu possuidor. (MARX, 2002, p. 201)

Portanto, o mínimo valor da força de trabalho é dado pelo valor dos meios de subsistência imprescindíveis ao ser humano. Abaixo dessa linha, a capacidade de trabalho não pode mais se conservar.

O intercâmbio entre capital e trabalho é determinado por dois processos distintos. Ao comprar a força de trabalho, o capital adquire o próprio trabalho, ou seja, ele adquire a capacidade de conservar-se e multiplicar-se. Essa faculdade não pode surgir do valor da mercadoria comprada, mas do seu valor de uso. Para o trabalhador, por outro lado, a permuta é feita pela venda de sua força de trabalho em troca de uma quantia de dinheiro, o salário. "Para o trabalhador, esse intercâmbio é um ato de circulação mercantil simples, no qual sua mercadoria (a força de trabalho) percorre a forma de circulação M-D-M. Enquanto isso, o capital realiza o ciclo oposto, definido pela forma D-M-D" (MARX, 1956, apud ROSDOLSKY, 2001, p. 173). Com efeito, para o trabalhador trata-se de um intercâmbio de equi- 
valentes - força de trabalho por preço do trabalho -, ao passo que para o capital, uma vez que o capitalista recebe mais valor do que dá, ocorre um intercâmbio que contraria as próprias leis do intercâmbio.

O aproveitamento da força de trabalho nada mais é que o próprio trabalho, de forma que o capitalista consome a força de trabalho fazendo o trabalhador trabalhar. Do mesmo modo, "para o trabalho reaparecer em mercadorias, tem de ser empregado em valores-de-uso, em coisas que sirvam para satisfazer necessidades de qualquer natureza" (MARX, 2002, p. 211). Do ponto de vista do capitalista, o processo ocorre "entre coisas que o capitalista comprou, entre coisas que lhe pertencem" (MARX, 2002, p. 219). Assim, o capital alinha o trabalho vivo junto a seus elementos materiais, os meios de produção. No processo de produção, os elementos objetivos do capital submetem-se ao trabalho: "De um lado, a matéria que compõe o capital deve ser elaborada, ou seja, consumida pelo trabalho; de outro, a mera subjetividade [...] deve ser superada, objetivando-se na matéria do capital" (MARX, 1956, apud ROSDOLSKY, 2001, p. 179).

Observemos, agora, o processo de produção e suas inerentes relações sociais sob o ponto de vista específico do valor. Imaginemos uma mercadoria cujo processo de produção envolva apenas capital constante, ou seja, zero trabalho humano. Nesse caso, pela lei da transferência ${ }^{3}$, todo o valor será transmitido à massa de produtos finais ${ }^{4}$, impossibilitando, assim, a criação de mais-valor. Esse exercício imaginativo pode lançar luz a um aspecto central do modo de produção capitalista. Com efeito, caso o trabalhador recebesse como pagamento todo o valor que produziu com sua força de trabalho, não haveria valor excedente e, consequentemente, o modo de produção capitalista se inviabilizaria. Contudo, o trabalhador rece-

3 Sobre a lei da transferência de valores, reportamos o leitor ao capítulo VI do Livro Primeiro de O capital (MARX, 2002).

4 Consideramos aqui a produção em condições sociais normais, ou seja, sem desperdício de matérias-primas, com intensidade média de trabalho etc. 
be, na realidade, apenas uma fração do valor que cria, consistindo o restante em mais-valia de propriedade do capitalista. Considerando uma jornada de trabalho de oito horas, o trabalhador usa, por exemplo, cinco horas para adicionar um valor à matéria equivalente ao seu salário diário. As três horas restantes, sendo tempo de mais-trabalho (sob o ponto de vista do trabalhador), serão convertidas em mais-valia (sob o ponto de vista do capitalista) ${ }^{5}$.

Dessa forma, o capital produz valor excedente por meio do valor de uso que adquiriu, ou seja, explorando trabalho alheio. Atentemos agora em um ponto: a mercadoria força de trabalho é obtida no mercado mediante uma transação como outra qualquer. Ora, mas não era justamente a esfera da circulação aquela em que predominava a igualdade, a liberdade e a reciprocidade? Sem dúvida, esse ponto merece alguma meditação. O princípio da circulação, como vimos, é a identidade entre trabalho e propriedade, uma vez que o indivíduo troca no mercado o produto resultante de seu trabalho por outro de mesmo valor. Porém, justamente o desenvolvimento desse princípio promove a inversão do direito de propriedade:

O direito de propriedade transforma-se, de um lado, no direito de apropriar-se de trabalho alheio e, de outro, no dever de reconhecer que o produto do próprio trabalho e até mesmo o próprio trabalho são valores que pertencem a outro. O intercâmbio de equivalentes - operação originária que fundamentava juridicamente o direito de propriedade - modificou-se até o ponto de tornar-se um intercâmbio aparente, pois a parte do capital intercambiada por força viva de trabalho é trabalho alheio apropriado sem que a ele se tenha dado um equivalente como contrapartida [...]. A relação de intercâmbio deixou cabalmente de existir, é mera aparência. (MARX, 1977, p. 413)

Desse modo, a consequência da lei de circulação é a separação radical entre o trabalho - que fica impossibilitado de se apropriar do pró-

5 Não pensamos que este seja o local apropriado para abordar a importante diferença entre mais-valia absoluta e mais-valia relativa. Contudo, reportamos o leitor à Parte Terceira do Livro Primeiro de O capital (MARX, 2002). 
prio produto - e a propriedade - que se efetua como direito ao trabalho alheio. Assim, a liberdade e a igualdade como fundamentos da troca simples realizam-se, no modo de produção capitalista, como desigualdade e dominação. Porém, a adesão classista à superfície da circulação e a ocultação das subterrâneas relações de produção conduzem à apologia do capital. Estamos diante, portanto, de uma formação ideológica.

\section{IV}

Foucault afirma, em um texto de 1983, que o seu objetivo nos últimos vinte anos fora "criar uma história dos diferentes modos pelos quais, em nossa cultura, os seres humanos tornaram-se sujeitos" (FOUCAULT, 1995, p. 231). Com isso, ele coloca-se na contramão da asserção bastante frequente no meio acadêmico de que seu objeto primordial de estudo é o poder. Esse equívoco não é casual: ao estudar os fenômenos de objetivação do sujeito, Foucault cria realmente uma analítica do poder. Nessa analítica, o que se evidencia não é uma teoria do poder e muito menos uma teoria do sujeito, mas uma cartografia de complexas relações de poder no interior das quais os sujeitos são objetivados.

Será preciso uma teoria do poder? Uma vez que uma teoria assume uma objetivação prévia, ela não pode ser afirmada como uma base para um trabalho analítico. Porém este trabalho analítico não pode proceder sem uma conceituação dos problemas tratados, conceituação esta que implica um pensamento crítico - uma verificação constante. (FOUCAULT, 1995, p. 232)

Desse modo, Foucault evita formular uma teoria do poder uma vez que tal teoria obstruiria a própria análise das relações de poder. Realmente, a cristalização de uma teoria acabaria por impor um molde fixo e morto à análise das diversas relações sociais concretas. No entanto, Foucault 
não se exime das conceituações necessárias; para isso, ele caracteriza o poder como "a multiplicidade de correlações de força imanentes ao domínio onde se exercem e constitutivas de sua organização" (FOUCAULT, 2003, p. 88). Assim, o poder é compreendido como o suporte móvel de uma dispersão material. Poder produzido e ameaçado por toda e qualquer relação concreta, uma vez que ele não é uma forma substancializada passível de ser conquistada. "Onipresença do poder: não porque tenha o privilégio de agrupar tudo sob sua invencível unidade, mas porque se produz a cada instante, em todos os pontos, ou melhor, em toda relação entre um ponto e outro" (FOUCAULT, 2003, p. 89).

Foucault não pôde formular uma teoria do poder pois este é o operador central de suas análises; em outras palavras, é a estratégia do seu pensamento. Por estratégia do pensamento não devemos entender uma perspectiva subjetivista, mas a condição de possibilidade do seu método analítico.

Em que consiste a materialidade do poder? Os mais diversos elementos se prestam a relações de poder: a configuração arquitetônica de um prédio residencial, os testes experimentais de uma disciplina científica, o jogo de silêncios no setting psicanalítico... Mas observemos: todos esses elementos são atravessados por algo, ou melhor, algo é sempre materializado pelas relações de poder; referimo-nos ao discurso.

Suponho que em toda sociedade a produção do discurso é ao mesmo tempo controlada, selecionada, organizada e redistribuída por certo número de procedimentos que têm por função conjurar seus poderes e perigos, dominar seu acontecimento aleatório, esquivar sua pesada e temível materialidade. (FOUCAULT, 2001a, p. 9)

A questão onde, afinal, está o perigo [do discurso]? (FOUCAULT, 2001 b, p. 8) norteia a aula inaugural de Foucault no Collège de France, intitulada A ordem do discurso. Assim, ao mesmo tempo em que enuncia 
os perigos do discurso, o autor constitui seu conceito. Penetremos, portanto, na ordem do discurso de Foucault.

Desde o século VII, se fortalece em nossa sociedade uma vontade de verdade que tenciona separar o que ela chama de "discursos verdadeiros" e "discursos falsos". Podemos tomar como exemplo dessa vontade o atravessamento do sistema penal por diversos saberes, tais como a sociologia, a psicologia, a medicina, a psiquiatria, "como se a própria palavra da lei não pudesse ser autorizada, em nossa sociedade, senão por um discurso de verdade" (FOUCAULT, 2001a, p. 19). Apenas um exemplo, sem dúvida, mas que mostra como a vontade de verdade exerce pressão sobre os discursos. Esse movimento pode ser deslocado para a Antiguidade: algo ocorreu no curto espaço que cinde os sofistas de Platão. Nesse ponto o discurso foi desarmado a ponto de tornar-se uma verdade não pelo que ele faz, mas pelo que ele diz; com isso, ele perdeu seu brilho de coisa viva, para tornar-se a manifestação de coisas mortas.

Desde que foram excluídos os jogos e o comércio de sofistas, desde que seus paradoxos foram amordaçados, com maior ou menor segurança, parece que o pensamento ocidental tomou cuidado para que o discurso ocupasse o menor lugar possível entre o pensamento e a palavra; parece que tomou cuidado para que o discurso aparecesse apenas como um certo aporte entre pensar e falar; seria um pensamento revestido de seus signos e tornado visível pelas palavras, ou, inversamente, seriam as estruturas mesmas da língua postas em jogo e produzindo um efeito de sentido. (FOUCAULT, 2001a, p. 46)

Teme-se, no discurso, sua dimensão combativa, sua materialidade revolta, seu riso de escárnio frente aos rococós da vontade de verdade. É necessário, portanto, mirar o fundo dos olhos dessa ordem do discurso:

Não se trata, aqui, de neutralizar o discurso, transformá-lo em signo de outra coisa e atravessar-Ihe a espessura para encontrar o que permanece silencioso aquém dele, e sim, 
pelo contrário, de mantê-lo em sua consistência, fazê-lo surgir na complexidade que Ihe é própria. Em uma palavra, quer-se, na verdade, renunciar às 'coisas', 'despresentificálas'; conjurar sua rica, relevante e imediata plenitude, que costumamos considerar como a lei primitiva de um discurso que dela só se afastaria pelo erro, esquecimento, ilusão, ignorância ou inércia das crenças e das tradições ou, ainda, desejo inconsciente, talvez, de não ver e de não dizer; substituir o tesouro enigmático das 'coisas' anteriores ao discurso pela formação regular dos objetos que só nele se delineiam; [...]. (FOUCAULT, 2004, p. 53)

Foucault não trabalha, portanto, com o discurso como um plano a ser ultrapassado tendo-se em vista a verdade que ele ocultaria ou manifestaria, mas sim com a análise dos procedimentos de produção de verdade no interior mesmo do discurso. Para isso, ele utiliza o conceito de formação discursiva, isto é, "um conjunto de regras anônimas, históricas, sempre determinadas no tempo e no espaço que definiram uma época dada, e para uma área social, econômica, geográfica ou lingüística dada, as condições de exercício da função enunciativa" (FOUCAULT, 1980, apud MAINGUENEAU, 1997, p. 14). No item a seguir, verificaremos a forma concreta com que Foucault opera esse conceito.

V

Em A casa dos loucos, texto publicado originalmente em 1975, Foucault se detém no exame do surgimento da antipsiquiatria ${ }^{6}$. Para tanto, ele retoma o processo histórico que configurou a relação médico-paciente a partir dos hospitais do século XVIII. Refaçamos, então, em linhas sucintas

6 Foucault inclui no movimento da antipsiquiatria - veremos o critério a seguir - uma gama de autores, tais como Bernheim, Laing, Basaglia e Cooper. Cabe ressaltar, em consonância com o pensamento foucaultiano, que a antipsiquiatria pode ser caracterizada como uma multiplicidade de elementos discursivos descontínuos que confluem para uma estratégia mais ou menos semelhante. 
esse percurso, a fim de verificar como Foucault trabalha concretamente com o conceito de formação discursiva.

O hospital no século XVIII era um lugar de manifestação da doença. Ao médico cabia o exercício de uma ação direta sobre ela de tal forma que permitisse a eclosão de sua verdade. Ele deveria invocar e criar as condições para a doença desenvolver todas as suas potencialidades intrínsecas e libertar-se de formas confusas e misturadas a outras doenças. Para isso, era necessário atocaiá-la e surpreendê-la em rituais e ocasiões privilegiados. Portanto, a relação médico-paciente de então era pautada por procedimentos de apreensão e produção - tratava-se de apanhar a verdade da doença em uma situação específica ocasionada pelo médico. A ação terapêutica encontraria aí sua possibilidade de exercício. A concepção de crise, noção médica presente até o final do século XVIII, é exemplar dessa dimensão:

A crise, tal como era concebida e exercida, é precisamente o momento em que a natureza profunda da doença sobe à superfície e se deixa ver. É o momento em que o processo doentio, por sua própria energia, se desfaz de seus entraves, se liberta de tudo aquilo que o impedia de completar-se e, de alguma forma, se decide a ser isto e não aquilo, decide o seu futuro - favorável ou desfavorável. Movimento em certo sentido autônomo, mas do qual o médico pode e deve participar. Este deve reunir em torno dela todas as conjunções que Ihe são favoráveis e prepará-la, ou seja, invocá-la e suscitá-la. Mas deve também colhê-la como se fosse uma ocasião, nela inserir sua ação terapêutica e combatê-la no dia mais propício. Sem dúvida, a crise pode ocorrer sem o médico, mas se este quiser intervir, que seja segundo uma estratégia que se imponha à crise como momento de verdade, pronta a subrepticiamente conduzir o momento a uma data que seja favorável ao terapeuta. No pensamento e na prática médica, a crise era ao mesmo tempo momento fatal, efeito de um ritual e ocasião estratégica. (FOUCAULT, 2001b, p. 114) 
No entanto, o hospital era também o local por excelência da ambiguidade. Uma outra figura protagonizava alianças e duelos imprecisos na noite das práticas hospitalares. Com efeito, junto à dimensão produtiva, outra perspectiva atravessava a relação médico-paciente: o conhecimento. Ao médico cabia conhecer a doença, para coagi-la a apresentar-se. A doença era suscitada para que pudesse ser desvelada em sua verdade. As espécies de doenças precisavam ser contempladas pelo olhar médico que as categorizava.

As grandes estruturas hospitalares instauradas no século XIX tomaram para si durante muito tempo esta dupla função. $E$ durante um século (1760-1860) a prática e a teoria da hospitalização, e de uma forma geral a concepção de doença, foram dominadas por esse equívoco: o hospital, estrutura de acolhimento da doença, deve ser um lugar de conhecimento ou um lugar de prova ${ }^{7}$. (FOUCAULT, 2001b , p. 119)

Coerção mútua que envolvia a produção da verdade no discurso hospitalar até o final do século XVIII. Práticas de constatação da verdade, que deveria ser desvelada ao olhar atento do médico conhecedor; e, ao mesmo tempo, rituais do acontecimento-verdade que deveria ser suscitado pelo médico astucioso. No hospital, a determinação dupla dessas práticas discursivas não era uma contradição, era seu modo possível de ser. Não se trata de uma etapa do conhecimento que, orientado pela razão, pôde superar-se em direção a uma forma em que a ciência atual pudesse enfim se reconhecer. O que está em pauta é antes um outro equilíbrio na distribuição entre poderes e saberes. A relação de poder médico-paciente envolvia, então, modos de sujeição que não mais podemos reconhecer integralmente em nós; e isso não equivale a afirmar peremptoriamente que estamos diante do progresso da objetividade científica. Assim, por

7 O termo "prova" é aqui empregado por Foucault em alusão a rituais jurídicos marcados pelo desafio entre acusador e acusado. Em tais rituais, a verdade era o efeito produzido pela determinação do vencedor. Assim, "prova", no trecho citado, refere-se a ocasiões de manipulação da produção da verdade. 
meio de um saber crítico, Foucault se esquiva de cometer essa ilusão retrospectiva tão frequente nos historiadores da medicina.

Circunscritos a esse duplo constrangimento, uma série de questionamentos e debates acalorados foram suscitados e, repentinamente, recolheram-se para a sombra. Questionamentos que envolviam o curso de uma doença normal - deveria levar à morte ou à cura ao término de sua evolução? Debates abrangendo a natureza pura ou complexa da doença - haveria apenas uma doença fundamental que se ramificaria em várias outras impuras ou, ao contrário, categorias irredutíveis de doenças? Enfim, um regime discursivo que ruiu com a imposição de um novo personagem na cena hospitalar. Curiosamente, toda a comoção causada por sua entrada abrupta no palco não armado foi instantaneamente abafada pelo silêncio de seus gestos precisos e econômicos:

Sabemos bem que a biologia de Pasteur simplificou prodigiosamente todos estes problemas. Determinando o agente do mal e fixando-o como organismo singular, permitiu que o hospital se tornasse um lugar de observação, de diagnóstico, de localização clínica e experimental, mas também de intervenção imediata, ataque voltado para a invasão microbiana. (FOUCAULT, 2001b, p. 119)

E ainda:

O lugar onde se produzirá a doença será o laboratório, o tubo de ensaio. Mas aí a doença não se efetua numa crise. Reduz-se seu processo a um mecanismo que pode ser aumentado, e se a coloca como fenômeno verificável e controlável. O meio hospitalar não tem mais que ser para a doença o lugar favorável para um acontecimento decisivo. Ele permite simplesmente uma redução, uma transferência, um aumento, uma constatação. A prova se transforma em teste na estrutura técnica do laboratório. (FOUCAULT, 2001b, p. 119-120) 
Com isso, toda uma tecnologia da verdade era expulsa dos hospitais e dava lugar a novas formas de sujeição e a novos esquemas de conhecimento. A verdade agora deve ser conhecida pela mediação de instrumentos e não mais ser atraída e apanhada por armadilhas engenhosas. Desarmado de seus antigos poderes, o médico vê a esfera do conhecimento científico ganhar força em suas práticas. Dentre seus méritos, impõe-se agora a competência em detrimento da astúcia. De certo modo, em consonância com suas mãos, que passaram a ser acusadas de transmissoras do mal, a verdade - antes suscitada e invocada - precisa ser esterilizada. Justamente lá onde os médicos se viam como argutos produtores da verdade crítica da doença, lá onde sua presença era mais fundamental do que em qualquer outro lugar, justamente lá eles foram colocados contra a parede e feridos de morte: suas mãos, longe de salvarem, traziam a própria doença em sua forma invisível ao paciente. Uma nova assepsia na produção da verdade será necessária a partir daí, e os próprios médicos serão encarregados de levar a cabo esse projeto.

Foucault faz, então, um corte rápido em sua escritura e desloca seu foco para a problemática da loucura:

Antes do século XVIII, a loucura não era sistematicamente internada, e era essencialmente considerada como uma forma de erro ou de ilusão. Ainda no começo da idade clássica, a loucura era vista como pertencendo às quimeras do mundo; podia viver no meio delas e só seria separada no caso de tomar formas extremas ou perigosas. Nestas condições compreende-se a impossibilidade do espaço artificial do hospital em ser um lugar privilegiado, onde a loucura podia e devia explodir sua verdade. Os lugares reconhecidos como terapêuticos eram primeiramente a natureza, pois que era a forma visível da verdade; tinha nela mesma o poder de dissipar o erro, de fazer sumir as quimeras. As prescrições dadas pelo médico eram de preferência a viagem, o repouso, o passeio, o retiro, o corte com o mundo vão e artificial da cidade. Esquirol ainda considerou isto quando, ao fazer os 
planos de um hospital psiquiátrico, recomendava que cada cela fosse aberta para a vista de um jardim. (FOUCAULT, 2001b, p. 120-121)

Com o internamento do doente mental, no século XIX, a loucura passa a ser distinguida como "desordem na maneira de agir, de querer, de sentir paixões, de tomar decisões, de ser livre" (2001a, p. 121). O que está em questão é menos o julgamento perturbado do que uma conduta irregular; menos o erro da razão - concepção essa que nos remete diretamente à Idade Clássica, que unia a loucura a outras figuras da marginalidade (FOUCAULT, 2002) - do que um descontrole das paixões. Nesse cenário, o asilo se aproxima do hospital do século XVIII, ou seja, nele a loucura deve se desenvolver em toda a sua plenitude. Mas não basta desmascarar a doença mental, é preciso que o asilo seja o local de confrontação de duas vontades. De um lado, o doente, cuja vontade e conduta se (des)caracterizam pela perturbação e pela irregularidade; de outro, o médico, cuja retidão da índole deve prevalecer ao término do embate. Trata-se de sobrepujar os arroubos loucos e colocar "no devido lugar" o caráter do paciente. Imposição de uma vontade sobre a outra num embate travado no solo da ordem discursiva moral.

Assim se estabelece a função muito curiosa do hospital psiquiátrico do século XIX: lugar de diagnóstico e de classificação, retângulo botânico onde as espécies de doenças são divididas em compartimentos cuja disposição lembra uma vasta horta. Mas também espaço fechado para um confronto, lugar de uma disputa, campo institucional onde se trata de vitória e submissão. O grande médico do asilo - seja ele Leuret, Charcot ou Kraepelin - é ao mesmo tempo aquele que pode dizer a verdade da doença pelo saber que dela tem, e aquele que pode produzir a doença em sua verdade e submetê-la, na realidade, pelo poder que sua vontade exerce sobre o próprio doente. (FOUCAULT, 2001b, p. 122) 
Em oposição ao hospital, no qual a função do médico como produtor da verdade dilui-se numa estrutura de conhecimento, no asilo essa função se intensifica ao extremo. Mas isso ocorreu em uma época em que o saber médico precisava se inscrever em um registro que destacasse o conhecimento e a constatação de fenômenos. O psiquiatra, como médico que é, deve fundamentar suas práticas em seu conhecimento. A condição de médico do psiquiatra o colocava na berlinda em conformidade com a medicina da época. Em outras palavras, o poder que o asilo dá ao psiquiatra deve ser inscrito em um discurso integrado à linguagem e ao saber médico exigidos então. A cumplicidade entre essas duas prerrogativas se faz de forma curiosa, de modo que a relação psiquiatra-paciente será estratégica na criação de uma nova sensibilidade:

O ponto de perfeição, miraculosa em demasia, foi atingido quando as doentes do serviço de Charcot, a pedido do poder-saber médico, se puseram a reproduzir uma sintomatologia calcada na epilepsia, isto é, suscetível de decifração, conhecida e reconhecida nos termos de uma doença orgânica. (FOUCAULT, 2001b, p. 123)

Para Foucault, a primeira enunciação incipiente do movimento que viria a se instaurar como antipsiquiatria surge com a crítica de que Charcot produzia abusivamente a própria realidade da doença, e não sua verdade crítica. Trata-se de questionar o poder médico em si mais até do que o conhecimento e a ciência médica. Se a tensão entre verdade invocada-produzida e verdade descoberta-conhecida precisou ser diluída com a inserção do discurso médico no registro da cientificidade, tratase agora de ocasionar abalos na psiquiatria com o questionamento dos fundamentos da relação de poder médico-paciente. "A partir daí creio que se pode compreender o que está em jogo na antipsiquiatria, e que não é absolutamente o valor da verdade da psiquiatria em termos de 
conhecimento, de precisão do diagnóstico ou de eficácia terapêutica." (FOUCAULT, 2001b, p. 126.)

$\mathrm{VI}$

Como pudemos ver, as diferenças entre os conceitos de ideologia e de formação discursiva não são irrisórias. A singularidade de cada conceito impossibilita até mesmo uma conclusão que sintetize satisfatoriamente todas as suas dessemelhanças. Gostaríamos, no entanto, de destacar algumas diferenças.

Rico é o interjogo que estabelece o pensamento marxista entre a ideologia e seu substrato material. É correto, nesse sentido, afirmarmos que Marx, ao estabelecer a crítica ao modo de produção capitalista, baliza os parâmetros metodológicos para uma compreensão das obras do espírito tais como, por exemplo, a filosofia - como reflexos ideológicos da organização social. A ideologia pode, nesse viés, ser definida como uma justificativa, no plano das ideias, de uma ordem socioeconômica instituída.

Para Foucault, a clássica questão da relação do "pensamento" com as "coisas" é deslizada e transfigurada pelo conceito de formação discursiva. Com efeito, a enunciação é tomada agora não como uma expressão mais ou menos deturpada de um pensamento que a sustente, mas como $\mathrm{o}$ ato de inserção do sujeito em uma instituição que o domina. $\mathrm{O}$ discurso, desse modo, invade a realidade, sendo a um só tempo dispositivo social e representação.

O método crítico-dialético de Marx permite ultrapassar as criações ideais do mundo reificado. Ao efetuar essa ultrapassagem, atinge-se o ponto vital do modo de produção capitalista. Dessa forma, o confronto com a ideologia tem como contrapartida necessária a transformação da organização social que a possibilita. Foucault, por sua vez, afirma a total impossibilidade 
de separação entre a ordem social e a discursiva. O discurso passa, então, a ser visto como um dispositivo social de sujeição que realiza concretamente os jogos de restrição/produção característicos das relações de poder.

Sim, pouco sobra em comum entre ideologia e discurso. Porém, uma importante convergência entre esses conceitos nas obras de Marx e Foucault merece ser abordada. Trata-se da oposição à filosofia do sujeito, ou seja, da confrontação com o indivíduo tomado como ser isolado e centrado em sua própria consciência como fundamento do devir histórico. Realmente, com os conceitos de práxis e ideologia, Marx desloca o sujeito de seu autocentramento e o insere em amplas categorias socioeconômicas. Foucault, por sua vez, ao analisar os procedimentos de produção de verdade no discurso, debruça-se sobre processos históricos de objetivação do sujeito que pouco têm a ver com a razão libertadora do Iluminismo. Nesse ponto solitário, as obras de Marx e Foucault tocam-se cúmplices, por um instante apenas, para logo se afastarem novamente.

\section{Marx's ideology and Foucault's discourse: Convergence and Distanciation}

\section{Abstract}

This paper identifies the concepts of ideology and discourse in the works of Marx and Foucault, respectively. It summarizes the Marxist analysis of the reversal of the laws of property as a consequence of the destruction of a specific ideology; and presents the archeology of the doctor-patient relationship, from the work of Foucault, as an example of the configuration of a particular discursive field. To conclude, the paper points to a distanciation and a convergence between the concepts in question.

Keywords: Ideology. Discourse. Marx, K. (1818-1883). Foucault, M. (1926-1984). 


\section{Referências}

BIRMAN, Joel. Mal-estar na atualidade: a psicanálise e as novas formas de subjetivação. Rio de Janeiro: Civilização Brasileira, 2003. 300 p.

FOUCAULT, Michel. Dois ensaios sobre o sujeito e o poder. In: DREYFUS, H.; RABINOW, P. Michel Foucault: uma trajetória filosófica. Rio de Janeiro: Forense Universitária, 1995. p. 231-249.

. A ordem do discurso. São Paulo: Loyola, 2001a. 79 p.

. A casa dos loucos. In: . Microfísica do poder. Rio de Janeiro: Graal, 2001b. p. 113-128. $551 \mathrm{p}$.

. História da loucura na idade clássica. São Paulo: Perspectiva, 2002.

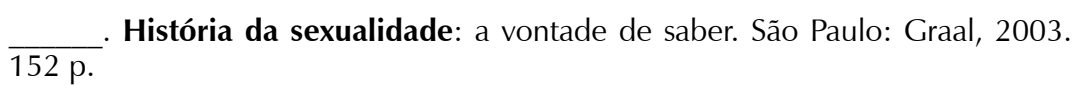
KOSIK, Karel. Dialética do concreto. Rio de Janeiro: Paz e Terra, 2002. 250 p. MAINGUENEAU, Dominique. Novas tendências em análise do discurso. Campinas: Pontes, 1997. $198 \mathrm{p}$.

MARX, Karl. O capital: crítica da economia política. v. 1-2. Rio de Janeiro: Civilização Brasileira, 2002. 966 p.

. Líneas fundamentales de la crítica de la economía política (grundrisse). v. 1. Barcelona: Crítica, 1977.

. Líneas fundamentales de la crítica de la economía política (grundrisse). v. 2. Barcelona: Crítica, 1978.

MARX, Karl; ENGELS, Friedrich. Teses contra Feuerbach. São Paulo: Abril Cultural, 1974. 413 p. (Coleção Os Pensadores, v. 35.)

. O manifesto comunista. Rio de Janeiro: Paz e Terra, 1998. 67 p.

. A ideologia alemã. São Paulo: Martins Fontes, 2007. 119 p.

ROSDOLSKY, Roman. Gênese e estrutura de $\boldsymbol{O}$ capital de Karl Marx. Rio de Janeiro: Eduerj; Contraponto, 2001. 623 p. 